September 2007 | Volume 65 | Number 1

Teachers as Leaders Pages 8-13

\title{
Overcoming the Obstacles to Leadership
}

\author{
Susan Moore Johnson and Morgaen L. Donaldson \\ Teacher leaders need support to overcome stubborn \\ barriers created by the norms of school culture- \\ autonomy, egalitarianism, and deference to seniority.
}

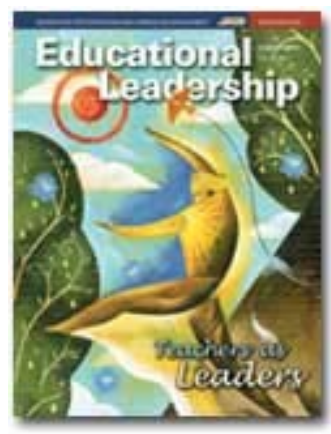

September 2007

Lacey's high school needed her talent and skills. Located in an urban, working-class community, the school was struggling to serve all students well and had failed to make Adequate Yearly Progress for two years running. As a social studies teacher, Lacey had developed considerable skill in teaching with a project-based format during her four years in the classroom, and her students were making steady progress as a result. But the reach of her expertise was limited by her classroom walls. Teachers in her school were dedicated to their students, but not to one another's growth. Whatever they had learned over time-how to do project-based learning, how to facilitate classroom discussions, how to effectively use technology-remained largely private. No one asked; no one told. As a result, the school's instructional capacity remained static, no more than the sum of individual teachers' strengths and deficits.

\section{Tempered Enthusiasm}

The standards and accountability movement has placed extraordinary demands on schools like Lacey's to improve instructional outcomes. To meet these demands, principals are appointing increasing numbers of teacher leaders to work with colleagues in such roles as instructional coach, lead teacher, mentor coordinator, and data analyst. Because recent large-scale retirements have left a shrinking pool of veteran teachers, principals often ask teachers in the second stage of their career, with 4 to 10 years of experience, to take on these specialized roles.

Second-stage teachers may find this opportunity attractive for several reasons (Donaldson, 2005; J ohnson \& the Project on the Next Generation of Teachers, 2004). First, many of them feel increasingly competent and confident in their work, and they want to share their acquired expertise with others. Lacey acknowledged, "I'm pretty good" at teaching social studies. She said that over time she had developed "a wider repertoire for teaching students at many levels" and had become more comfortable in her classroom and her school. Research confirms Lacey's sense of increasing skill and effectiveness. On average, students of fourth-year teachers learn more than students of first-year teachers (Rockoff, 2004).

Second, becoming a teacher leader promises to reduce isolation. When they begin their career, many of today's new teachers expect to work in teams but are dismayed to find themselves working alone day after day. Lacey expressed regret about the lack of collegial interaction in her school: "It's just you alone in your classroom. You don't get into each other's classrooms very often." 
Third, becoming a teacher leader offers an opportunity to vary one's responsibilities and expand one's influence. Many second-stage teachers want to have a hand in making decisions about how their school operates. Lacey criticized "the way it's set up right now. You don't move up. You do the same thing the whole time." She liked the idea of using her growing expertise to help "change the bigger picture."

Thus, competent and confident second-stage teachers like Lacey welcome opportunities to collaborate with colleagues, learn, grow, and expand their influence. Having taken on these roles, how do second-stage teachers fare?

With colleagues at the Project on the Next Generation of Teachers, we interviewed 20 secondstage teachers who had assumed roles as teacher leaders (Donaldson et al., in press). These teachers worked in a range of settings: elementary and secondary schools, urban and suburban communities, and several metropolitan areas across the United States. We found that, although these teachers were initially enthusiastic about their new roles, they encountered unforeseen challenges. The schools in which they worked remained largely unchanged, with an egg-crate structure that reinforced classroom boundaries and a professional culture that discouraged teacher leadership. These findings suggest that, to reap the full benefits of teacher leadership, school administrators need to provide formal support structures and build leadership roles into the structure of the school.

\section{Business as Usual}

On the whole, few schools have reorganized to make the most of the expertise teacher leaders offer. Usually, the new roles are simply appended to a flat, compartmentalized school structure in which classroom teachers continue to work alone. Instructional coaches, for example, are expected to make periodic classroom visits and advise fellow teachers about their practice. But this model does little to change business as usual. The classroom teacher remains isolated and in charge, while the teacher leader arrives only occasionally as a visitor.

Teacher leaders' marginal status is underscored by the fact that their positions are typically funded with outside grants from year to year, rather than being built into a school's regular budget. Thus, the positions remain add-ons to the school program. When the funds run out, the school can eliminate these roles without seriously disrupting its operations.

In addition, teacher leaders' roles are seldom well defined. Principals often regard teacher leaders as a source of extra help in a school that is strapped for human resources. As a result, many teacher leaders spend their time as apprentices or assistants in administration-supervising the cafeteria, subbing for absent staff, or overseeing the logistics of testing-rather than using their instructional expertise to improve teaching at the school.

\section{A Triple Threat}

Teacher leaders' efforts to share their expertise can also be undermined by the culture of teaching. In fact, the professional norms of teaching present a daunting challenge to teacher leaders who are asked to improve their colleagues' instruction. Our interviews suggested that colleagues often resist these teacher leaders' work because they see it as an inappropriate intrusion into their instructional space, an unwarranted claim that the teacher leader is more expert than they, and an unjustified promotion of a relative novice to a leadership role. Thus, the norms of autonomy, egalitarianism, and deference to seniority that have long characterized the work of teaching remain alive and well in schools.

\section{Protecting Autonomy}

Teacher leaders said that they were often rebuffed when they offered to observe in colleagues' classrooms or made suggestions about teaching. Mai, a mathematics coach and fifth-year teacher, was responsible for organizing professional development meetings, demonstrating 
sample lessons for other teachers, and offering feedback on their teaching. She reported, "I can't even enter one teacher's room because he is not open to me coming to his room while he teaches." She explained further, "There are other teachers, especially teachers who have been teaching for a long time, who aren't comfortable with being observed, period." The school's teachers' union representative told Mai she could not "evaluate or make judgments, good or bad, on teachers or teaching practice. So I can't say, 'You did a great job with behavior management,' even though that's nice feedback to get." By denying her entrance to their classrooms and restricting the kind of feedback she could provide, Mai's colleagues asserted their right to decide what and how to teach.

\section{Ensuring Egalitarianism}

Teachers also questioned the premise that a peer could possess expert knowledge or presume to act on it. Clark, a 10th-year elementary teacher, reported that his colleagues assumed that he and the other instructional facilitator felt superior and avoided him. Frustrated, Clark contrasted his current, strained interactions with the relaxed, collegial relationships that he had enjoyed before he became an instructional facilitator.

Others told of being criticized by peers because their role granted them unusual privileges or special access. Anna, a math consultant and fifth-year elementary teacher, taught full time and ran after-school classes on how to use the district's math curriculum. Several of her peers resented the fact that she could get substitutes to cover her classes so that she could observe and coach other teachers. Anna's role also required her to coordinate often with her principal, which seemed to create distrust and jealousy among her colleagues. It was, she said, "hard not to come off as the principal's pet."

\section{Reinforcing Seniority}

- Teacher leaders in the second stage of their career often said that their colleagues viewed them as too young or inexperienced to have such a role. When Mai, age 29, tried to assist a veteran teacher in using the district's math curriculum, she was asked confrontationally, "And how old are you?" Even those who were not so young and had entered teaching after another career were criticized for their inexperience. Dave, a 45-year-old who had been teaching for seven years, was supposed to help others implement a new math curriculum and analyze student test data in his elementary school. Some of his colleagues, although younger, still questioned his appointment, asking, "Why him? Why didn't I get that job? I've been doing this for 18 years."

\section{Teacher Leaders Cope}

Such opposition was discouraging-sometimes demoralizing. To persist with their leadership work, the second-stage teachers devised strategies to minimize their colleagues' resistance and the emotional burden it placed on them. The following coping strategies often helped teacher leaders avoid provoking other teachers' fears, deflect opposition, and diminish tensions when they arose. But these strategies also tended to legitimize the traditional culture of teaching and its norms of autonomy, egalitarianism, and deference to seniority.

\section{Wait to Be Drafted}

Although teacher leaders were supposedly chosen for their special expertise, few roles came with explicit qualifications or procedures for selection. When no established process existed for choosing teacher leaders, colleagues often saw appointments as acts of favoritism by the principal. They raised objections on the basis of claims of seniority, the default mechanism for distributing special rights and privileges among teachers.

Anticipating that veterans might criticize them for their inexperience or question their qualifications, many of the teacher leaders whom we interviewed refrained from volunteering for leadership positions until they were drafted. For example, Eric, a 6th grade instructional coach, 
anticipated the problem of "coming in as some sort of hotshot." Although he wanted the position, Eric hesitated when the principal first offered it; he waited until his more experienced colleagues expressed no interest in the role and encouraged him to take it. He reasoned that with this approach he could counter any opposition by arguing, "You're the ones who didn't want the role, so I'm expecting you guys to give me a little bit more support." This strategy, he thought, would oblige them "to be on board."

\section{Work with the Willing}

Some teacher leaders who encountered resistance or opposition scaled back their efforts and worked only with their most willing colleagues. In doing so, they affirmed their colleagues' right to choose whether to accept their assistance. However, they also reduced their potential schoolwide influence.

Sarah had eight years of experience when she was appointed science curriculum coordinator for the two elementary schools in her district. In this role, she was supposed to help other teachers create and conduct inquiry-based science lessons. Other teachers had scant knowledge of her responsibilities, however, and administrators did little to help her gain access to classrooms and team meetings. Given this ambiguity and lack of support, Sarah chose to work with teachers who sought her out and ignore those who did not. She explained that she was on her own and limited by traditional boundaries: "I'm not an administrator, so I can't tell someone that they need to have me in their room." Therefore, she decided to help those who already welcomed her expertise. She found that working with these colleagues kept her busy, and she had little need to "drum up business" among other teachers.

Similarly, Lauren, an eighth-year teacher whose role as an elementary school literacy coordinator was also undefined and poorly supported, backed off from the challenges she encountered: "I 've kind of given up the fight with the teachers who constantly cancel on me or don't want me in their room." Instead, she focused on improvements made by teachers who sought her help: "That's what inspires you and keeps you moving," she declared.

\section{Work Side by Side}

Other teacher leaders tried to foster joint ownership of the reforms their roles were designed to champion and support. They cast themselves as sources of support, not supervisors, permitting their colleagues to decide how to incorporate proposed changes into their classrooms. In doing so, they often reinforced the belief that teacher leaders are no more expert than their peers.

Anna, for example, said she was advised by more senior colleagues not to present information "in a way that feels suffocating." Anna believed that by casting herself as a collaborator, rather than an authority, she enabled her veteran colleagues to take some ownership over changes to their practice.

Similarly, Kelly-an elementary school literacy coach and sixth-year teacher-described herself to her colleagues as a "facilitator" who connected them to resources that they could use to improve their practice rather than telling them how to teach. By allowing the teachers they worked with to determine how the reforms would play out in their classrooms, Anna and Kelly recognized and reinforced other teachers' autonomy. Their role was to support each teacher's approach to reform, not direct it.

In summary, the teacher leaders whom we interviewed coped with a traditional school organization and a teaching culture that prized and protected norms of egalitarianism, seniority, and autonomy. Because their roles were ill defined, these teacher leaders had to devise ways to be seen as legitimate and to gain access to teachers and classrooms without being rejected or becoming disheartened.

\section{Better Support for Teacher Leaders}


Our interviews with teachers in the second stage of their career suggest that many want to vary their responsibilities, collaborate with peers, and influence teaching beyond their classrooms. In many ways, they are ideal candidates to provide the teacher leadership that schools urgently need. However, their accounts also reveal that their experience as teacher leaders often fails to fulfill their expectations and may do little to build their schools' instructional capacity.

Most teacher leaders we interviewed were left to define their own roles, which proved to be more of a burden than an opportunity. In the absence of any professional framework or established set of differentiated responsibilities to provide guidance or legitimacy for their roles, teacher leaders' offers of advice often strained their relationships with other teachers. No amount of skill, enthusiasm, or determination in these teacher leaders could fundamentally change the structure of schooling or culture of teaching.

We do not infer from this study that roles for teacher leaders are doomed. Rather, we conclude that the roles must be introduced deliberately and supported fully. Informal roles with unpredictable funding will never be taken seriously. To be viable, these roles must have welldefined qualifications, responsibilities, and selection processes.

In Peer Assistance and Review programs in districts such as Toledo, Ohio; Montgomery County, Maryland; and Rochester, New York, consulting teachers advise and evaluate all beginning teachers and some struggling veterans. The success and sustainability of these programs, the first of which was introduced in Toledo in 1981, suggests that school officials should focus on establishing and supporting a system of long-term, well-defined roles for teacher leaders.

Our interviews made it clear that the principal can make or break the role of teacher leader. It was not enough for the principal to be a passive supporter, as was the case for most of the teacher leaders we interviewed. Rather, he or she needed to anticipate the resistance that teacher leaders might encounter from colleagues and help them broker the relationships they would need to do their work.

A few teacher leaders said that their principals helped by having what one called a "big game plan," which explained to all the staff how teacher leaders would contribute to the school's effort to achieve its goals. Principals can build support for a teacher leader's role by explaining its purpose, establishing qualifications and responsibilities, encouraging applicants for the position, and running a fair selection process. They can work with the schedule and available resources to incorporate the work of teacher leaders into the structure of the school and provide common planning time, substitute coverage for peer observations, and use of faculty meetings for professional development. They can guarantee that teacher leaders are not diverted to take on administrative tasks. Because school culture is so crucial to the success of these roles, teachers must see the principal's practices and priorities as reinforcing a new set of norms that promote collaborative work, bridge classroom boundaries, and recognize expertise.

But principals' efforts alone will not enable teacher leaders to succeed. Fundamentally, the success or failure of teacher leaders will depend on their relationships with their colleagues. Teacher leaders need professional development that prepares them to respond to colleagues' resistance respectfully while helping these teachers improve their practice.

\section{Redefining the Norms of Teaching}

The traditional norms of teaching-autonomy, egalitarianism, and seniority-exert a powerful and persistent influence on the work of teachers. They reinforce the privacy of the individual's classroom, limit the exchange of good ideas among colleagues, and suppress efforts to recognize expert teaching. Ultimately, they cap a school's instructional quality far below its potential.

If these norms remain dominant, many talented teachers who desire collaboration and expanded influence will become frustrated and leave education in search of another place to build a fulfilling career. Even more troubling -if these norms persist, they will continue to dissuade teachers from 
sharing vital knowledge about teaching and learning with their colleagues.

Schools cannot afford to lose promising teachers or squander opportunities to better serve students. It will take the efforts of all educators-district administrators, principals, teacher leaders, and teachers themselves-to redefine the norms of teaching and support teacher leaders in their work so that every school's instructional capacity expands to meet its students' needs.

\section{References}

Donaldson, M. L. (2005, April). On barren ground: How urban high schools fail to support and retain newly tenured teachers. Paper presented at the annual meeting of the American Educational Research Association, Montreal, Quebec, Canada.

Donaldson, M. L., Johnson, S. M., Kirkpatrick, C. L., Marinell, W. H., Steele, J. L., \& Szczesiul, S. A. (in press). Angling for access, bartering for change: How second-stage teachers experience differentiated roles in schools. Teachers College Record.

Johnson, S. M., \& the Project on the Next Generation of Teachers. (2004). Finders and keepers: Helping new teachers survive and thrive in our schools. San Francisco:

Jossey-Bass.

Rockoff, J. (2004). The impact of individual teachers on student achievement: Evidence from panel data. American Economic Review, 94(2), 247-252.

Authors' note: This article is based in part on analysis and argument presented in "Angling for Access, Bartering for Change: How Second-Stage Teachers Experience Differentiated Roles in Schools," by M. Donaldson, S. Johnson, C. Kirkpatrick, W. Marinell, J. Steele, and S. Szczesiul, in press, Teachers College Record.

Susan Moore J ohnson is Carl H. Pforzheimer Jr. Professor of Teaching and Learning, Harvard Graduate School of Education, Cambridge, Massachusetts; susan_moore_johnson@harvard.edu. Morgaen L. Donaldson is an advanced doctoral student at the Harvard Graduate School of Education; Donaldmo@gse.harvard.edu.

Copyright $\odot 2007$ by Association for Supervision and Curriculum Development

(c) Copyright ASCD. All rights reserved. 